\title{
Complementation Analysis of the Aliphatic Amidase Genes of Pseudomonas aeruginosa
}

\author{
By ROBERT DREW \\ Department of Biochemistry, University College London, Gower Street, London WCIE 6BT, UK
}

(Received 29 May 1984; revised 26 July 1984)

\begin{abstract}
A plasmid, pCL34, capable of autonomous replication in Escherichia coli and Pseudomonas aeruginosa has been constructed which carries the promoter and structural gene (amiE) for $P$. aeruginosa amidase, but not the regulator gene (amiR). Plasmid pCL34 has been mobilized from $E$. coli to $P$. aeruginosa using the broad host range plasmid RP4. Complementation studies were performed in $P$. aeruginosa strains carrying various amidase mutations. Measurements of amidase activity in the recipients under inducing, non-inducing and repressing conditions showed trans-complementation by the chromosomally located regulator gene product. These results confirmed the positive control model for amidase gene expression. Levels of amidase expression seen during these studies were approximately threefold higher than in the parental, amidase-positive strains.
\end{abstract}

\section{INTRODUCTION}

Studies on the control of gene expression in Pseudomonas aeruginosa have been hampered by the inability to perform classical complementation analysis with merodiploids. However, using the wide host range IncP-1 plasmid R68.45 (Haas \& Holloway, 1976), R' plasmids from P. aeruginosa have been isolated by selection in Escherichia coli (Hedges \& Jacob, 1977; Hedges et al., 1977), from recombination deficient $P$. aeruginosa (Holloway, 1978) and $P$. putida (Morgan, 1982). Such $R^{\prime}$ plasmids have been found to be unstable on transfer to recombination proficient $P$. aeruginosa strains and not useful for complementation studies.

In $E$. coli, studies of the mechanism of control of gene expression by complementation analysis have been utilized in the examination of classic negatively controlled systems, such as the lactose operon (Jacob \& Monod, 1961), of more complex positively controlled systems including Dserine deaminase (Bloom et al., 1975; Carothers et al., 1980), and of those with aspects of both positive and negative control, the arabinose operon (Englesberg et al., 1965, 1969). In these cases the dominance relationships between regulator gene products in the merodiploid state have provided one line of evidence towards defining the mechanisms of regulation.

Expression of the aliphatic amidase gene (amiE) of P. aeruginosa (Kelly \& Clarke, 1962) is under the control of the closely linked regulator gene product (Brammar et al., 1967). Farin \& Clarke (1978) concluded that the $a m i R$ gene product exerted positive control on the expression of the $a m i E$ gene. Amidase synthesis is also subject to catabolite repression by succinate (Smyth \& Clarke, $1975 a$ ). Mutants showing resistance to catabolite repression fall into at least two classes: (i) those closely linked to the amidase genes and considered to be up-promoter mutants and (ii) those unlinked to the amidase genes (Smyth \& Clarke, $1975 a, b$ ). Hybrid $\lambda$ ami recombinant bacteriophages constructed in vitro have been described previously (Drew et al., 1980). The amidase structural gene and its promoter from an up-promoter mutant have been subcloned into plasmid pBR322 and the structural gene located (Clarke et al., 1981) and partially sequenced (W. J. Brammar, personal communication).

I have deleted non-essential $P$. aeruginosa DNA from the plasmid recombinant in vitro and constructed a hybrid vector by joining plasmid pBR322-amiE (pCL28) to an IncQ group plasmid, pQSR 136 (Meyer et al., 1979). IncQ plasmids have been developed as cloning vectors for 
use in Pseudomonas and related organisms (Bagdasarian et al., 1981; Bagdasarian \& Timmis, 1982; Hennam et al., 1982). These plasmids are generally about $10 \mathrm{~kb}$ in size, are non-conjugative, have a copy number of $10-15$ and replicate in both $E$. coli and $P$. aeruginosa (Grinter \& Barth, 1976). The hybrid plasmids were used for complementation studies in $P$. aeruginosa.

\section{METHODS}

Bacteria. The bacterial strains used are listed in Table $1(a$ and $b)$.

Plasmids. The plasmids used are listed in Table 2.

$M e d i a$. The $E$. coli strains were grown in L broth (Lennox, 1966) supplemented where necessary with streptomycin (Sm) $\left(50 \mu \mathrm{g} \mathrm{ml}^{-1}\right)$, ampicillin (Ap) $\left(50 \mu \mathrm{g} \mathrm{ml}^{-1}\right)$, tetracycline (Tc) $\left(20 \mu \mathrm{g} \mathrm{ml}^{-1}\right)$. The $P$. aeruginosa strains were grown in Oxoid no. 2 nutrient broth supplemented as necessary with streptomycin $\left(250 \mu \mathrm{g} \mathrm{ml}^{-1}\right)$ and/or carbenicillin $\left(250 \mu \mathrm{g} \mathrm{ml}^{-1}\right)$.

For amidase assays the growth medium for P. aeruginosa was the basal medium of Brammar \& Clarke (1964) with ammonium sulphate $(0.1 \%, w / v)$ as nitrogen source and sodium succinate $(1 \%, w / v)$ or sodium lactate $(1 \%$, $\mathrm{w} / \mathrm{v})$ as carbon sources. Lactamide $(0.2 \%, \mathrm{w} / \mathrm{v})$ was added for the inducing medium and butyramide $(0.2 \%, \mathrm{w} / \mathrm{v})$ for the repressing medium (Clarke, 1972). The minimal medium was supplemented with streptomycin $\left(250 \mu \mathrm{g} \mathrm{ml}^{-1}\right)$ and carbenicillin $\left(250 \mu \mathrm{g} \mathrm{ml}^{-1}\right)$ as appropriate.

The medium for growth of $E$. coli was the basal medium of Clarke \& Laverack (1983) containing glucose $(0.5 \%$, $\mathrm{w} / \mathrm{v})$ or sodium succinate $(0.5 \%, \mathrm{w} / \mathrm{v})$ as additional carbon source. This was supplemented with amino acids at $0.003 \%(w / v)$ for growth of strain JA221. Inducing and repressing amides were added as for $P$. aeruginosa, and Sm and $\mathrm{Ap}$ (both at $50 \mu \mathrm{g} \mathrm{ml}^{-1}$ ) were added as appropriate.

\section{Table 1. Bacterial strains}

(a) E. coli

\section{Strain}

HB 101

JA221

$\mathrm{C} 600$

\section{Genotype} (relevant features)

$h s d R$ recA rpsL20

$h s d R \operatorname{rec} A$

thr leu thi

(b) $P$. aeruginosa

Strain

Genotype

PAO1161

PACl

PAC 308

PAC111

PAC324

PAC142

PAC 326

PAC438

PAC623

PAC452

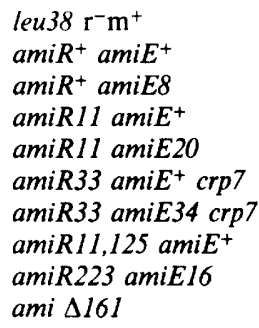
$\mathrm{amiR}^{+} \mathrm{amiE}^{+}$ $a m i R^{+}$amiEs amiR33 amiE ${ }^{+}$crp 7 amiR33 amiE34 crp7 amiR 11,125 amiE ${ }^{+}$ ami $\Delta l 61$

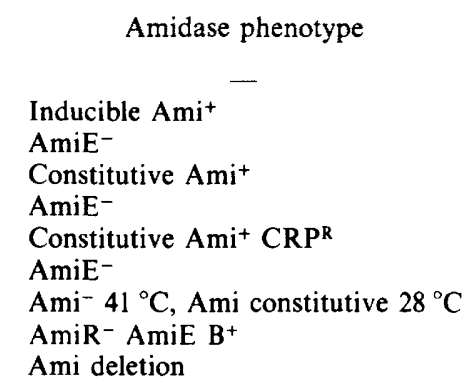

\section{Reference}

Rodriguez et al. (1977)

Clarke \& Carbon (1978)

Harayama et al. (1980)

\section{Reference}

Dunn \& Holloway (1971)

Kelly \& Clarke (1962)

Brammar et al. (1967)

Brammar et al. (1967)

Betz et al. (1974)

Smyth \& Clarke (1975a)

Betz \& Clarke (1972)

Farin \& Clarke (1978)

Farin \& Clarke (1978)

Day (1975)

Table 2. Plasmids.

\begin{tabular}{lrll} 
Plasmid & $\begin{array}{r}\text { Size } \\
(\mathbf{k b})\end{array}$ & Markers* & \multicolumn{1}{c}{ Reference } \\
pBR322 & $4 \cdot 4$ & Ap Tc & Bolivar et al. $(1977)$ \\
pJB950 & $9 \cdot 1$ & Ap Ami & Clarke et al. $(1981)$ \\
pCL28 & $6 \cdot 9$ & Ap Ami & This paper \\
pQSR136 & $11 \cdot 3$ & Sm & Meyer et al. $(1979)$ \\
pCL31 & $18 \cdot 2$ & Sm Ap Ami & This paper \\
pCL34 & $18 \cdot 2$ & Sm Ap Ami & This paper \\
pTH10 & $60 \cdot 4$ & Ap Km Tc & Harayama et al. (1980)
\end{tabular}

* The phenotypic abbreviations are for resistance to ampicillin, tetracycline, streptomycin, kanamycin and amidase-positive character. 
Plasmid DNA preparations. (i) Large-scale DNA preparations were made using the sheared lysate method of Bazaral \& Helinski (1968). (ii) In some of the experiments transformed colonies were examined for the presence of plasmid DNA by a modified version of the method of Goodman \& MacDonald (1979). Overnight cultures ( $1 \mathrm{ml}$ ) in broth were pelleted, drained and frozen at $-70^{\circ} \mathrm{C}$. Frozen pellets were resuspended in $100 \mu \mathrm{l}$ spheroplast forming mixture and lysed by addition of $50 \mu 12 \%$ Sarkosyl (Bazaral \& Helinski, 1968). After a clearing spin the supernatant was subjected to RNAase treatment, extracted with phenol/chloroform and the DNA ethanol precipitated and dried. DNA was dissolved in water and subjected to restriction enzyme analysis. (iii) In later experiments plasmid DNA was isolated from transformed cultures of $E$. coli and P. aeruginosa by the method of Birnboim \& Doly (1979).

Enzymes and chemicals. Restriction endonucleases HindII, HpaII, PstI, SalI and $\lambda$ DNA were purchased from Miles Laboratories, Stoke Poges, Slough, UK. EcoRI, HindIII, SmaI and TaqI were purchased from BCL, Lewes, UK. AvaI, KpnI, SstII, XhoI and XorII were purchased from BRL. T4 DNA ligase was from CP Laboratories, Bishop's Stortford, UK. Most chemicals were AR grade. Caesium chloride was from BDH and HGT Agarose was from Miles Laboratories.

Endonuclease digestion and gel electrophoresis. Endonuclease digestions were carried out as prescribed by the manufacturers. Agarose gel electrophoresis was carried out as described by Clarke et al. (1981) using a Tris/borate buffer system (Peacock \& Dingman, 1969) and gels were photographed using Polaroid $4 \times 5$ Landfilm type 55 .

Ligase reactions. Restricted DNA to be ligated was mixed together and ethanol precipitated in $2 \%$ (w/v) sodium acetate at $-70{ }^{\circ} \mathrm{C}$. Samples recovered by centrifugation were dried under vacuum and resuspended in $10 \mathrm{~mm}-$ Tris/ $\mathrm{HCl}, \mathrm{pH} 7 \cdot 5,100 \mathrm{mM}-\mathrm{NaCl}$. Concentrated ligase cocktail was added and the DNA ligated overnight at $14^{\circ} \mathrm{C}$ as described previously (Drew et al., 1980).

Transformations. Samples of plasmid DNA were used to transform $E$. coli strain JA221 made competent by the method of Mandel \& Higa (1970) as described previously (Drew et al., 1980). After growth in $\mathrm{L}$ broth for $90 \mathrm{~min}$ to allow plasmid genes to be expressed portions were overlaid in soft agar onto $\mathrm{L}$ plates containing antibiotics.

$P$. aeruginosa strains were made competent by a modification of the above procedure. Cultures were grown, harvested and resuspended in $0.5 \mathrm{vol} .0 .1 \mathrm{M}-\mathrm{MgCl}_{2}$. The cells were harvested, resuspended in 0.2 vol. $0 \cdot 1 \mathrm{M}-\mathrm{MgCl}_{2}$ and iced for $20 \mathrm{~min}$. Finally, the cells were harvested and resuspended in 0.04 vol. $0.1 \mathrm{M}-\mathrm{CaCl}_{2}$ and stored on ice for $60 \mathrm{~min}$ prior to DNA additions. Treatment was then as for $E$. coli.

Conjugation and mobilization using plasmid RP4. Approximately $1 \times 10^{8}$ donor and recipient cells from overnight cultures in broth were patch mated on $L$ plates for $4 \mathrm{~h}$ at $30^{\circ} \mathrm{C}$. Dilution buffer $(0.2 \mathrm{ml}$ per plate $)$ was added and the cells were lifted off with a sterile glass spreader and pipette. The cells were pelleted, washed and serial dilutions plated onto appropriate selective plates at the desired temperature.

Amidase assays. Amidase was assayed in intact cells by the transferase assay (Brammar \& Clarke, 1964) using acetamide as substrate. Bacterial growth was measured by absorption at $670 \mathrm{~nm}$. Amidase specific activities are expressed as $\mu \mathrm{mol}$ acethydroxamate produced $\mathrm{min}^{-1}$ (mg bacteria) ${ }^{-1}$.

\section{RESULTS}

\section{Construction of plasmids $p C L 31$ and $p C L 34$}

Plasmid pJB950 (Clarke et al., 1981) is a derivative of pBR322 containing a $5.1 \mathrm{~kb}$ insert of P. aeruginosa PAC433 DNA between the HindIII and SalI targets (Fig. 1a). Partial DNA sequence analysis has shown that the amidase $\mathrm{N}$-terminal coding sequence begins $244 \mathrm{bp}$ from the HindIII target (W. J. Brammar, personal communication). From the size of the amidase protein, approximately 340 amino acids, the coding region cannot extend beyond $1.3 \mathrm{~kb}$ from the HindIII site. To reduce the size of pJB950 and remove non-essential PAC433 DNA, pJB950 was digested with XhoI, ligated and transformed into $E$. coli HB101 with selection for ampicillin resistance. Thirty resistant colonies were picked and checked for amidase activity on solid medium (Drew et al., 1980). Plasmid DNA was isolated from ampicillin-resistant, amidasepositive clones. Two clones carrying plasmids smaller than pJB950 were investigated further. Plasmid DNA from these was subjected to restriction enzyme analysis with AvaI, HindIII, KpnI, PstI, SalI, SmaI, SstII, XhoI and XorII. Analysis showed that in both of these isolates the DNA between the $X$ hoI targets at 2.38 and $4.23 \mathrm{~kb}$ on pJB950 had been deleted and in addition the $X$ hoI target was not reconstituted (data not shown). One of these two isolates, pCL28, composed of approximately $2.7 \mathrm{~kb}$ from pBR322 and $3.1 \mathrm{~kb}$ of PAC433 DNA, was utilized further (Fig. $1 b)$.

To construct a broad host range plasmid carrying the amidase structural gene, pCL28 DNA isolated from E. coli HB101 and pQSR136 DNA from P. aeruginosa PAO1162 were linearized 

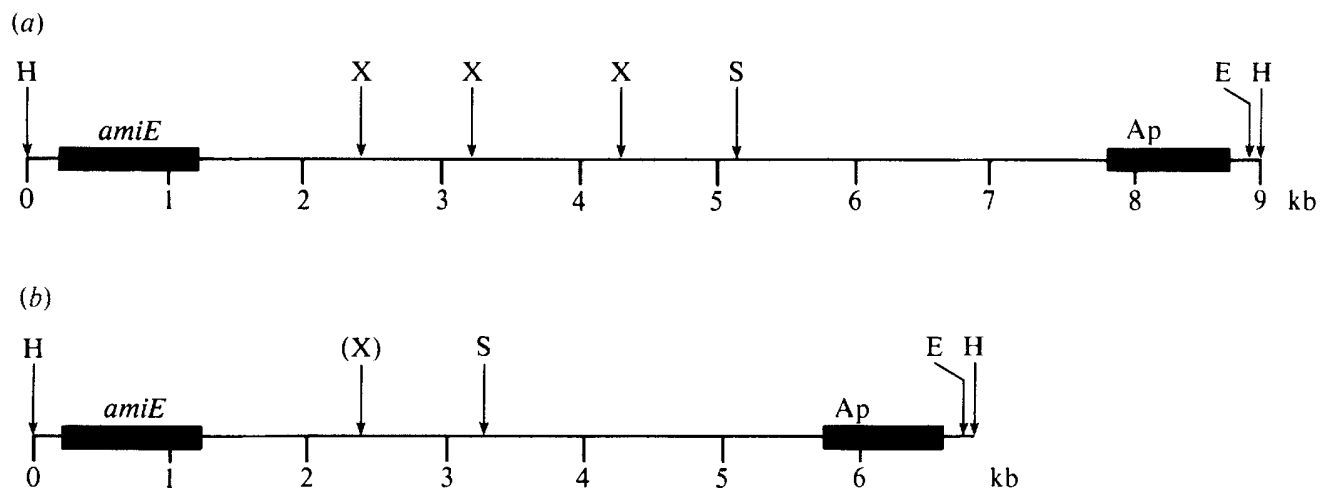

Fig. 1. Restriction maps of pBR322/ami plasmids. (a) Map of pJB950 (Clarke et al., 1981) linearized from single HindIII target. Positions of genes and HindIII (H), XhoI (X), SalI (S) and EcoRI (E) targets are to scale $(\mathrm{kb})$. (b) Map of pCL28 showing in vitro constructed deletion of XhoI fragments 2.38 to $4.23 \mathrm{~kb}$. The $X$ hoI target $(\mathrm{X})$ has not been reconstituted.

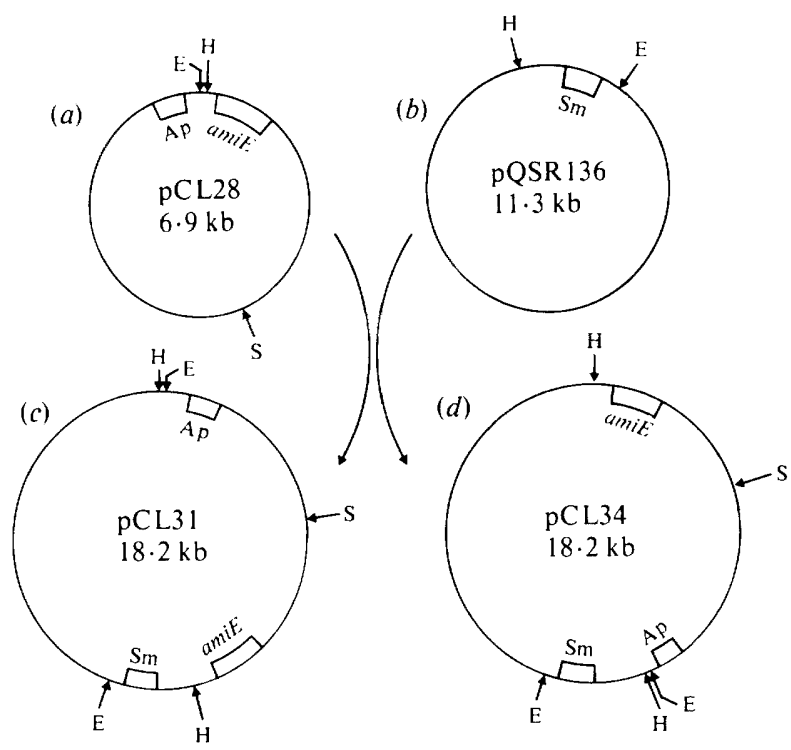

Fig. 2. Construction of plasmids pCL31 and pCL34. (a) Map of pCL28 with approximate gene locations and HindIII (H), SalI (S) and EcoRI (E) targets. (b) Map of pQSRI36 showing location of streptomycin resistant determinant and Eco RI (E) and HindIII (H) targets. $(c, d)$ Maps of pCL31 and pCL34 showing gene locations and restriction enzyme targets.

with HindIII, ligated and used to transform E. coli JA221 to ampicillin/streptomycin resistance. Resistant clones were isolated at a frequency of 86 per $\mu \mathrm{g}$ donor DNA. Plasmid DNA isolated from 12 of these transformants was analysed by digestion with HindIII, SalI and Eco RI. Two isolates were identified as carrying hybrid plasmids in opposite orientations (Fig. 2): pCL31 and pCL34 are distinguished by the asymmetric location of Eco RI targets.

\section{Transformation studies with plasmids}

Transformation of $E$. coli JA221 with plasmids of increasing sizes showed a reduction in transformation frequency (Table 3) as size increased. pBR322 $(4.4 \mathrm{~kb})$ yielded $2.2 \times 10^{6}$ transformants per $\mu \mathrm{g}$ DNA; pCL28 $(6.9 \mathrm{~kb})$ yielded $8.4 \times 10^{5}$ transformants per $\mu \mathrm{g}$ DNA; and pQSR136 $(11.3 \mathrm{~kb})$ yielded $8.0 \times 10^{4}$ transformants per $\mu \mathrm{g}$ DNA. E. coli JA221 appeared to be a better transformation recipient than strain $\mathrm{HB} 101$ by an order of magnitude. $P$. aeruginos $a$ was 
Table 3. Transformation frequencies of plasmids

$\begin{array}{lrlllc}\text { Plasmid } & \begin{array}{r}\text { Size } \\ (\mathrm{kb})\end{array} & \text { Host } & \text { Recipient } & \text { Selection* } & \begin{array}{c}\text { No. transformants } \\ \text { per } \mu \mathrm{g} \text { DNA }\end{array} \\ \text { pBR322 } & 4 \cdot 4 & \text { HB101 } & \text { JA221 } & \text { Ap } & 2.2 \times 10^{6} \\ \text { pBR322 } & 4.4 & \text { HB101 } & \text { HB101 } & \text { Ap } & 3.6 \times 10^{5} \\ \text { pCL28 } & 6.9 & \text { HB101 } & \text { JA221 } & \text { Ap } & 8.4 \times 10^{5} \\ \text { pQSR136 } & 11.3 & \text { PAO1162 } & \text { JA221 } & \text { Sm } & 8.0 \times 10^{4} \\ \text { pQSR136 } & 11.3 & \text { PAO1162 } & \text { PAC308 } & \text { Sm } & 8.2 \times 10^{2} \\ \text { pQSR136 } & 11 \cdot 3 & \text { PAO1162 } & \text { PAC623 } & \text { Sm } & 3.5 \times 10^{3} \\ \text { pQSR136 } & 11 \cdot 3 & \text { PAO1162 } & \text { PAO1162 } & \text { Sm } & 9.9 \times 10^{2} \\ \text { pCL31 } & 18.2 & \text { JA221 } & \text { PAC308 } & \text { Cb Sm } & 0 \\ \text { pCL34 } & 18.2 & \text { JA221 } & \text { PAC308 } & \text { Cb Sm } & 0 \\ \text { pCL31 } & 18.2 & \text { JA221 } & \text { PAO1162 } & \text { Cb Sm } & 0 \\ \text { pCL34 } & 18.2 & \text { JA221 } & \text { PAO1162 } & \text { Cb Sm } & 1.1 \times 10^{2}\end{array}$

* Antibiotic selection was for resistance to ampicillin, streptomycin and carbenicillin.

Table 4. Amidase activity in E. coli

Cells were incubated overnight at $37^{\circ} \mathrm{C}$ and amidase activity was measured in intact cells by the transferase assay (Brammar \& Clarke, 1964). Amidase activity is expressed as $\mu$ mol acethydroxamate formed $\min ^{-1}$ (mg bacteria) $)^{-1}$. Values expressed are the mean of three experiments.

$\begin{array}{lcccccc}\text { Strain } & \text { Plasmid } & \text { Glucose } & \begin{array}{c}\text { Glucose/ } \\ \text { lactamide }\end{array} & \text { Succinate } & \begin{array}{c}\text { Succinate/ } \\ \text { lactamide }\end{array} & \begin{array}{c}\text { Succinate/ } \\ \text { butyramide }\end{array} \\ \text { JA221 } & - & 0.05 & 0 & 0 & 0 & 0 \\ \text { JA221 } & \text { pCL28 } & 0.22 & 0 \cdot 24 & 0 \cdot 11 & 0 \cdot 14 & 0.14 \\ \text { JA221 } & \text { pCL31 } & 0.79 & 0.82 & 0 \cdot 89 & 1.03 & 0.92 \\ \text { JA221 } & \text { pCL34 } & 0.42 & 0.49 & 0.19 & 0 \cdot 17 & 0.24\end{array}$

transformed much less readily than $E$. coli by the broad host range Q group plasmid. Frequencies were reduced by 100 -fold for pQSR136 transformed into PAC or PAO strains (Table 3). Attempts to transform pCL31 and pCL34 directly into PAC strains with selection for carbenicillin/streptomycin resistance were unsuccessful. Strain PAO1161 has been described as a good recipient for transformation and contains the conjugative plasmid FP2. pCL31 and pCL34 were transformed into strain PAO1161 with drug resistance as the selection. Only pCL34 transformants were obtained at a frequency of $1.1 \times 10^{2}$ per $\mu \mathrm{g}$ DNA. Agarose gel electrophoresis of mini plasmid DNA preparations confirmed the presence of pCL34 (data not presented).

\section{Amidase expression in E. coli strains}

Amidase expression in $E$. coli JA221 carrying various ami plasmids was measured under inducing, non-inducing and repressing conditions (Table 4). Wild-type $E$. coli normally shows no growth on acetamide medium and gives little or no colour reaction in the transferase assay. Strain JA221 carrying pCL28 showed low constitutive amidase expression under all growth conditions. This suggested that the $a m i \mathrm{R}$ gene was absent or non-functional. There was no evidence to indicate if this amidase expression originated from the amidase promoter or from the remnants of the pBR322 tetracycline resistance promoter at the HindIII join. E. coli JA221 containing the hybrid plasmids pCL31 and pCL34 showed higher levels of amidase activity (Table 4). Amidase expression was constitutive and not subject to induction or repression. Expression from pCL34 was approximately twofold higher than from pCL28, and that from pCL31 between five- and tenfold higher. These increases were not investigated further but it was envisaged that the increased activity was due to read-through transcription from promoters located in pQSR136. 


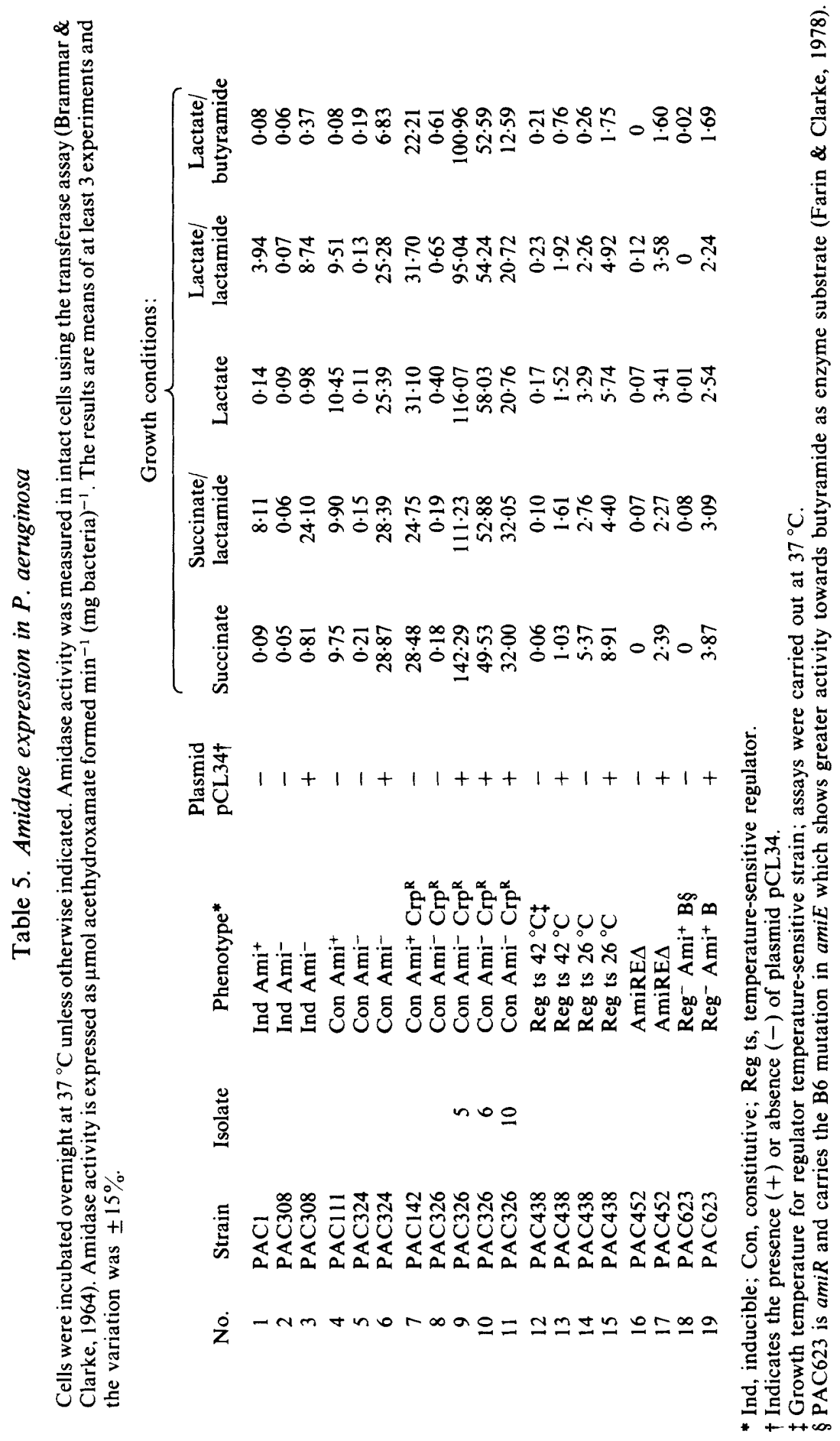




\section{Plasmid mobilization experiments}

To study complementation of amidase, attempts were made to mobilize plasmids pCL31 and pCL34 into $P$. aeruginosa PAC strains carrying various structural and regulator gene mutations. Attempts to use strain PAO1162(FP2, pCL34) as donor into strain PAC308 amiR ${ }^{+} a m i E$ were unsuccessful. It has been reported that mobilization of IncQ group plasmids by FP2 is of the order of $1 \times 10^{-7}$ (Willets \& Crowther, 1981) and restriction systems in the recipient (unpublished observations) would be expected to reduce this further.

This was overcome by using the broad host range plasmid RP4 to mobilize pCL31, pCL34 from $E$. coli to P. aeruginosa. A derivative of RP4, pTH10, that was temperature-sensitive for replication, was used to facilitate loss of the mobilizing plasmid from the transconjugants. Plasmid pTH10 was transferred into strains JA221(pCL31) and JA221(pCL34) from E. coli C600 by plate mating. Transconjugants were obtained and shown to contain both plasmids by antibiotic resistance determinations and restriction enzyme analysis of plasmid DNA isolations (data not presented.

Strains JA221(pTH10, pCL31) and JA221(pTH10, pCL34) were used as donors to mobilize the non-conjugative plasmids into $P$. aeruginosa PAC308. Antibiotic selection gave transconjugants from the JA221(pCL34) cross only. HindIII and SalI restriction enzyme analysis of plasmid DNAs isolated from the transconjugants showed that only pCL34 was present after subculturing at $37^{\circ} \mathrm{C}$. The successful donor in this experiment was used to mobilize pCL34 into various other PAC recipients. By this means pCL34 was transferred into strains PAC324, PAC326, PAC438, PAC623 and PAC452. Restriction enzyme analysis of plasmid DNA isolated from transconjugants from all of these crosses showed the presence of only one plasmid corresponding to pCL34.

\section{Complementation studies}

Gene expression studies from plasmids pCL28, pCL31 and pCL34 in E. coli had indicated that plasmid pCL34 was functionally amiR: deletion, amiP: constitutive, amiE: positive. Amidase activity was measured in $P$. aeruginosa transconjugants under inducing, non-inducing and repressing conditions. Cells were grown in minimal medium with succinate or lactate as carbon sources. Lactamide and butyramide were added as inducer or amide analogue repressor, respectively. These two amides are hydrolysed poorly by amidase, and enzyme activity was not required for bacterial growth.

Under these conditions wild-type and mutant $P$. aeruginosa strains showed their expected phenotypes (Table 5). Strain PACl was induced by lactamide (line 1), PAC111 showed constitutive enzyme synthesis which was repressed by butyramide (line 4) and PAC142 showed high constitutive synthesis due to the unlinked mutation conferring resistance to catabolite repression (line 7). Strain PAC438, which contains a regulator (amiR) temperature-sensitive mutation, showed low constitutive enzyme synthesis at $26^{\circ} \mathrm{C}$, which was sensitive to butyramide repression, and no enzyme activity at $42^{\circ} \mathrm{C}$ (lines 12 and 14).

Amidase activity was lacking in the amiE derivatives of these strains, PAC308, PAC 324, PAC326 and also in PAC452 and PAC623. Strain PAC452 had previously been characterized as containing a deletion of at least the amidase structural gene and PAC623 is an amiR strain derived from an inducible strain which produces the mutant $B$ amidase.

Amidase expression from plasmid pCL34 in strain PAC308 was controlled by the chromosomally located $a m i R$ gene product (line 3 ). Under non-inducing conditions (succinate or lactate) low amidase expression was detectable, which was somewhat repressed by growth in the presence of butyramide. Under inducing conditions (succinate/lactamide or lactate/lactamide) high levels of amidase activity were observed: three times that of the fully induced wild-type under similar conditions.

Constitutive amidase expression from pCL34 was found in hosts carrying mutant constitutive amiR genes: PAC324 (line 6) and PAC326 (lines 9-11). Activity was measured in six independently isolated transconjugants of PAC324 all of which showed activities some threefold higher than the parental strain PAC111 (line 4). This activity was partially butyramide repressible, showing control by the chromosomal amiR gene product. Greater variation was 

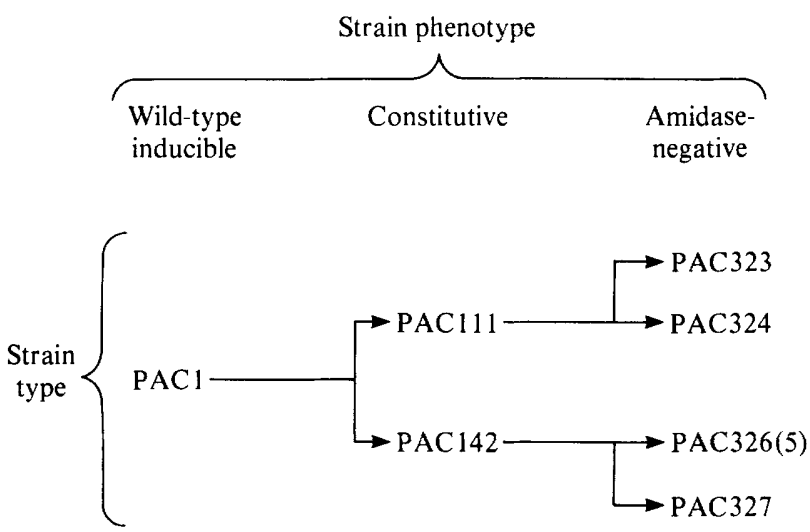

Amidase activity

in strain containing

plasmid pCL34

Fig. 3. Derivation of amidase-negative mutants from constitutive parents. Amidase-specific activities are given as $\mu \mathrm{mol}$ acethydroxamate produced $\mathrm{min}^{-1}(\mathrm{mg} \text { bacteria })^{-1}$. Amidase activity was measured in whole cells after overnight growth in succinate basal medium (see Methods).

found in isolates of strain PAC326 containing pCL34. Three such isolates gave specific activities between 20 and 100 (lines 9-11) compared with the parental strain PAC142 whose specific activity ranged from 22 to 32 under these growth conditions. This finding was unexpected since the isolates were thought to be identical. However, these values were found to be reproducible on retesting.

Expression from plasmid pCL34 in the temperature-sensitive regulator mutant PAC438 at $42{ }^{\circ} \mathrm{C}$ (line 13) showed low regulator-independent expression that was repressed slightly by growth on butyramide. Expression at $26^{\circ} \mathrm{C}$ was presumed to be from both plasmid and chromosomal amiE genes. The amidase activity of strain PAC438 at $26^{\circ} \mathrm{C}$ was doubled in the presence of plasmid pCL34 (lines 14 and 15). However, the specific activities were reduced by growth in medium containing butyramide, since the thermolabile regulator in this strain is sensitive to butyramide repression.

There was some amidase synthesis from plasmid pCL34 in P. aeruginosa strains thought to lack a functional amiR product. Expression from pCL34 in PAC452 and PAC623 (lines 17 and 19) was constitutive under all growth conditions at levels some $20-40 \%$ of the fully induced wildtype PAC1. Since PAC623 had been genetically defined as an amiR mutant and PAC452 as a deletion, amidase expression was presumed to result from interactions of host RNA polymerase with either the amidase promoter of pCL34 or the up-stream pQSR136 sequences.

The results of the complementation analysis shown in Table 5 allowed undefined amidasenegative mutations to be located. Complementation with pCL34 which gave high constitutive activity located the ami mutations of strains PAC324 and PAC326 into the structural gene amiE. Similarly, the low activities with pCL34 in strains PAC323 and PAC327 indicated that regulator gene mutations had caused the amidase-negative phenotype (Fig. 3).

\section{Analysis of pCL34 transconjugants}

It was considered that the different levels of amidase activity seen in PAC326(pCL34) isolates might have resulted from recombination. To examine this possibility, plasmid-free segregants were obtained from isolates 5 and 10 (see Table 5). A small number of cells were used to inoculate antibiotic-free minimal medium and the inoculum was grown overnight. Serial dilutions of the overnight culture were plated on solid medium with or without antibiotics to measure the frequency of plasmid loss. Plasmid-free segregants were isolated at high frequency and tested for amidase activity. Less than 1 in 300 colonies screened retained pCL34 after non-selective growth from both isolates. Five independent colonies from isolates 5 and 10 were tested and all had specific activities $<1.0$ under all growth conditions. Thus the different activities exhibited by 
(a)

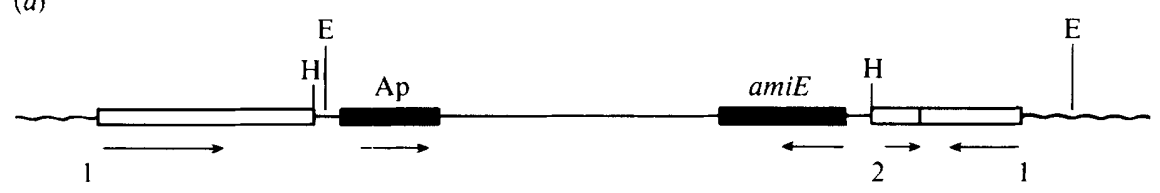

(b)

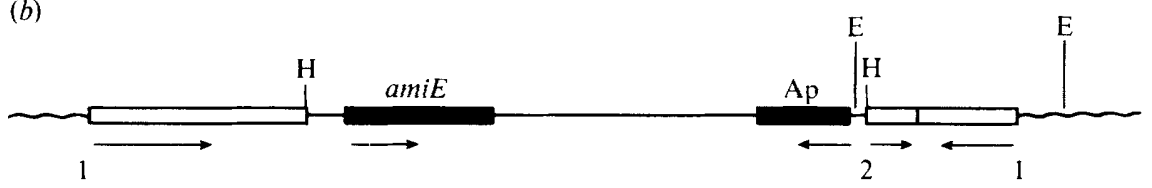

Fig. 4. Map showing location of $a m i E$ gene with respect to Tn5 promoters in plasmids pCL31 (a) and pCL34 $(b)$. Neither the size of genes nor the size of inverted repeats or the distances between them are drawn to scale. Symbols: $\cdots$, pQSR136 DNA; —_, pCL28 DNA; $\square$, inverted repeats of Tn5; $\square$, location of genes on pCL28; $\leftarrow$, indicates origin and direction of transcription. (1) Transposition function transcripts and (2) transcription from neomycin phosphotransferase II promoter. Tn 5 information from Rothstein et al. (1980). Location of HindIII (H) and Eco RI (E) restriction enzyme targets are shown.

isolates PAC326(pCL34/5) and PAC326(pCL34/10), of 100 and 26, respectively, could not be explained by recombination between the plasmid-carried up-promoter/structural gene and the chromosomal sequences but may have been due to differences in copy number of their plasmids.

\section{DISCUSSION}

Complementation analysis using cloned genes offers an alternative to $R^{\prime}$ or $F^{\prime}$ plasmid isolation in bacterial species where $R^{\prime}$ isolation is difficult. Cloned genes offer the advantages of being physically defined by restriction enzyme mapping and have the potential for in vitro manipulations to locate DNA sequences of importance. Thus specific deletions and insertions may be constructed to investigate the sequences controlling gene expression. The hybrid plasmid pCL34 which is able to replicate in both $P$. aeruginosa and $E$. coli carries a fragment of the $P$. aeruginosa chromosome containing the amidase structural gene and an up-promoter mutation, but lacks a functional regulator activity. Transduction analysis of the amidase genes had shown about 90\% linkage between the structural and regulator genes (Brammar et al., 1967), but the lack of nearby markers meant that the gene order was unknown.

Amidase expression from pCL28 in E. coli was at low constitutive levels under all growth conditions, showing the absence of regulated gene expression. It is proposed that this expression results from low-affinity interaction between RNA polymerase and either the amidase promoter or the remnants of the tetracycline resistance promoter at the HindIII join. In vitro transcription studies have indicated that $E$. coli RNA polymerase can initiate transcription from a restriction enzyme fragment containing just the $P$. aeruginosa DNA sequences (C. Turberville, personal communication).

Higher constitutive levels of enzyme activity were seen from the hybrid replicons pCL31 and pCL34 in E. coli. Expression from pCL31 was five times greater than that from pCL28 and expression from pCL34 was twice as great as that from pCL28. In plasmids pCL31 and pCL34 the $a m i E$ gene was located downstream from Tn 5 sequences present in pQSR136. The different levels of constitutive amidase expression from the two hybrids was thought to result from readthrough transcription from $\mathrm{Tn} 5$ promoters (Fig. 4). Tn 5 has been investigated with regard to expression of transposition functions and neomycin phosphotransferase (NPT) II activity and the promoters for these functions have been identified (Rothstein et al., 1980). However, it is not readily apparent from this information how read-through transcription could account for the different amidase activities in E. coli. In pCL31, which shows the higher activity, the amidase promoter lies back-to-back with the NPT II promoter which is itself part of the non-homologous inverted repeat of $\mathrm{Tn} 5$. In pCL34 transcription originating at the left end of the inverted repeat and running into the amidase gene could explain the enhanced expression compared with pCL28. 
Expression studies from pCL34 in $P$. aeruginosa PAC strains confirmed the lack of amidase regulator function on the cloned fragment. The presence of a functional amiR gene in the cis configuration would be expected to show very high amidase expression similar to the parental strain PAC433 which has a specific activity of $>50$. Instead, in the absence of functional $R$ protein (PAC623, pCL34) low constitutive enzyme levels are found. These low levels were an average of ninefold higher in $P$. aeruginosa amiR strains than in $E$. coli, presumably reflecting increased RNA polymerase/promoter interactions.

Under inducing conditions with PAC308(pCL34) and non-inducing conditions with PAC324(pCL34) and PAC326(pCL34) complementation was observed. For this to occur it is apparent that the regulator protein must function in trans. The results show dominance of regulator-inducible or regulator-constitutive over regulator-negative and confirm the positive control model for amidase expression proposed by Farin \& Clarke (1978). The cloned $a m i R$ amiPcon $a m i E^{+}$fragment is complemented by chromosomally located $a m i R^{+} a m i P^{+} a m i E$ and also by $a m i R^{\text {con }} a m i P^{+} a m i E$ with the predicted results. Complementation studies with pCL34 allowed previously uncharacterized amidase-negative mutations to be assigned to the regulator or structural genes, respectively.

However, these studies suggested that amidase regulation may be somewhat more complex than a simple positive control. Amidase synthesis in amiR hosts carrying pCL34 was at a low constitutive level, but in $a m i R^{+} E$ hosts under non-inducing or repressing conditions expression from the plasmids was further reduced (Table 5). This may be taken to indicate that the regulator protein has a dual function. With the wild-type system, in the absence of inducer, the regulator may act as a repressor to reduce amiE transcription to a very low level. During induction the regulator protein combined with inducer stimulates amiE transcription to a high level.

Dominance relationships between various constitutive and inducible alleles now being investigated may elucidate this aspect of amidase regulation.

Many thanks to Pat Clarke and Diane Cousens for many useful discussions and to Nick Lowe for excellent technical assistance. Thanks are extended to Bill Brammar and Chris Turberville for the communication of unpublished results. Financial support for this work was provided by the Science and Engineering Research Council.

\section{REFERENCES}

Bagdasarian, M. \& Timmis, K. N. (1982). Host : vector systems for gene cloning in Pseudomonas. Current Topics in Microbiology and Immunology 96, 47-67.

Bagdasarian, M., LURz, R., RuCKert, B., Franklin, F. C. H., Bagdasarian, M. M., Frey, J. \& Timmis, K. N. (1981). Specific-purpose plasmid cloning vectors, II. Broad host range, high copy number, RSF1010 derived vectors and a host-vector system for gene cloning in Pseudomonas. Gene 16, 237-247.

BaZARAL, M. \& Helinski, D. R. (1968). Circular DNA forms of colicinogenic factors E1, E2 and E3 from Escherichia coli. Journal of Molecular Biology 36, 185194.

BeTZ, J. L. \& ClaRKE, P. H. (1972). Selective evolution of phenylacetamide-utilizing strains of Pseudomonas aeruginosa. Journal of General Microbiology 73, 161174.

Betz, J. L., Brown, J. E., Clarke, P. H. \& Day, M. (1974). Genetic analysis of amidase mutants of Pseudomonas aeruginosa. Genetical Research 23, 335359.

Birnboim, H. C. \& Doly, J. (1979). A rapid alkaline extraction procedure for screening recombinant plasmid DNA. Nucleic Acids Research 7, 1513-1523.

BloOM, F. R., MCFall, E., Young, M. C. \& Carothers, A. M. (1975). Positive control in the D- serine deaminase system of Escherichia coli K 12 . Journal of Bacteriology 121, 1092-1101.

Bolivar, F., Rodriguez, R. L., Green, P. J., Betlach, M. V., Heyneker, H. L., Boyer, H. W., Crosa, J. H. \& Falkow, S. (1977). Construction and characterisation of new cloning vehicles, II. A multipurpose cloning system. Gene 2, 95-113.

Brammar, W. J. \& Clarke, P. H. (1964). Induction and repression of Pseudomonas aeruginosa amidase. Journal of General Microbiology 37, 307-319.

Brammar, W. J., Clarke, P. H. \& Skinner, A. J. (1967). Biochemical and genetic studies with regulator mutants of the Pseudomonas aeruginosa 8602 amidase system. Journal of General Microbiology 47 , 87-102.

Carothers, A. M., Heincz, M. C. \& McFall, E. (1980). Position effect on expression of $d s d$ genes cloned onto multicopy plasmids. Journal of Bacteriology 142, 185-190.

Clarke, L. \& Carbon, J. (1978). Functional expression of cloned yeast DNA in Escherichia coli: specific complementation of argininosuccinate lysase $(\operatorname{arg~} \mathrm{H})$ mutations. Journal of Molecular Biology 120, 517532.

Clarke, P. H. (1972). Biochemical and immunological comparison of aliphatic amidases produced by 
Pseudomonas species. Journal of General Microbiology 71, 241-257.

Clarke, P. H. \& Laverack, P. D. (1983). Expression of the arg $F$ gene of Pseudomonas aeruginosa in Pseudomonas aeruginosa, Pseudomonas putida, and Escherichia coli. Journal of Bacteriology 154, 508-512.

Clarke, P. H., Drew, R. E., Turberville, C., Brammar, W. J., Ambler, R. P. \& Auffret, A. D. (1981). Alignment of cloned amiE gene of Pseudomonas aeruginosa with the $\mathrm{N}$ terminal sequence of amidase. Bioscience Reports 1, 299-307.

DAY, M. J. (1975). Genetic studies with Pseudomonas aeruginosa strains. $\mathrm{PhD}$ thesis, University of London.

Drew, R. E., Clarke, P. H. \& Brammar, W. J. (1980). The construction in vitro of derivatives of bacteriophage lambda carrying the amidase genes of Pseudomonas aeruginosa. Molecular and General Genetics 177, 311-320.

DunN, N. W. \& Holloway, B. W. (1971). Pleiotropy of $p$-fluorophenylalanine resistant and antibiotic hypersensitive mutants of Pseudomonas aeruginosa. Genetical Research 18, 185-197.

Englesberg, E., IrR, J., Power, J. \& Lee, N. (1965). Positive control of enzyme synthesis by gene $C$ in the L-arabinose system. Journal of Bacteriology 90, 946957.

EnglesberG, E., Squires, C. \& Meronk, F., JR. (1969). The L-arabinose operon in Escherichia coli $\mathrm{B} / \mathrm{r}$ : a genetic demonstration of two functional states of the product of a regulator gene. Proceedings of the National Academy of Sciences of the United States of America 62, 1100-1107.

FARIN, F. \& ClaRke, P. H. (1978). Positive regulation of amidase synthesis in Pseudomonas aeruginosa. Journal of Bacteriology 135, 379-392.

Goodman, H. M. \& MacDonald, R. J. (1979). Cloning of hormone genes from a mixture of cDNA molecules. Methods in Enzymology 68, 75-90.

Grinter, N. J. \& BARTH, P. T. (1976). Characterization of $\mathrm{SmSu}$ plasmids by restriction endonuclease cleavage and compatibility testing. Journal of Bacteriology 128, 394400.

HaAs, D. \& Holloway, B. W. (1976). R factor variants with enhanced sex factor activity in Pseudomonas aeruginosa. Molecular and General Genetics 144, 243 251.

Harayama, S., Tsuda, M. \& IIno, T. (1980). High frequency mobilisation of the chromosome of Escherichia coli by a mutant of plasmid RP4 temperature sensitive for maintenance. Molecular and General Genetics 180, 47-56.

HedGes, R. W. \& JACOB, A. E. (1977). In vivo translocation of genes of Pseudomonas aeruginosa onto a promiscuously transmissible plasmid. FEMS Microbiology Letters 2, 15-19.

Hedges, R. W., Jacob, A. E. \& Crawford, I. P.
(1977). Wide ranging plasmid bearing the Pseudomonas aeruginosa tryptophan synthase genes. Nature, London 267, 283-284.

Hennam, J. F., Cunningham, A. E., Sharpe, G. S. \& ATHERTON, K. T. (1982). Expression of eukaryotic coding sequences in Methylophilus methylotrophus. Nature, London 297, 80-82.

HollowaY, B. W. (1978). Isolation and characterisation of an $\mathrm{R}^{\prime}$ plasmid in Pseudomonas aeruginosa. Journal of Bacteriology 133, 1078-1082.

JACOB, F. \& MONOD, J. (1961). Genetic regulatory mechanisms in the synthesis of proteins. Journal of Molecular Biology 3, 318-356.

Kelly, M. \& Clarke, P. H. (1962). An inducible amidase produced by a strain of Pseudomonas aeruginosa. Journal of General Microbiology 27, 305316.

LENNOX, E. S. (1966). Transduction of linked characters of the host of bacteriophage Pl. Virology 1 , 190-206.

MANDEL, M. \& HIGA, A. (1970). A calcium-dependent bacteriophage DNA infection. Journal of Molecular Biology 53, 159-162.

Meyer, R., Boch, G. \& Shapiro, J. (1979). Transposition of DNA inserted into deletions of the Tn5 kanomycin resistance element. Molecular and General Genetics 171, 7-13.

MORGAN, A. F. (1982). Isolation and characterisation of Pseudomonas aeruginosa $\mathbf{R}^{\prime}$ plasmids constructed by interspecific mating. Journal of Bacteriology 149, 654-661.

Peacock, A. C. \& Dingman, C. W. (1969). Resolution of multiple ribonucleic acid species by polyacrylamide gel electrophoresis. Biochemistry 6, 18181827.

Rodriguez, R. L., Tait, R., Shine, J., Boliva, F., Heyneker, H., Betlach, M. \& Boyer, H. (1977). Characterisation of tetracycline and ampicillin resistant plasmid cloning vehicles. In Molecular Cloning of Recombinant DNA, pp. 73-84. Edited by W. A. Scott \& R. Werner. New York: Academic Press.

Rothstein, S. J., Jorgensen, R. A., Yin, J. C.-P., YoNG-Di, Z., JoHNSTON, R. C. \& REZNIKOFF, W. S. (1980). Genetic organization of Tn5. Cold Spring Harbor Symposia on Quantitative Biology 45, 99-105.

SMyth, P. F. \& Clarke, P. H. (1975a). Catabolite repression of Pseudomonas aeruginosa amidase: the effect of carbon source on amidase synthesis. Journal of General Microbiology 90, 81-90.

SMyth, P. F. \& Clarke, P. H. (1975b). Catabolite repression of Pseudomonas aeruginosa amidase: isolation of promoter mutants. Journal of General Microbiology 90, 91-99.

Willetts, N. \& Crowther, C. (1981). Mobilisation of the non-conjugative IncQ plasmid RSF 1010 Genetical Research 37, 311-316. 